\title{
Nutritional Status, Dietary Patterns and associated factors among out-of-school Adolescents in Ibadan, Nigeria
}

Folake Olukemi SAMUEL BSc, MSc, $\mathrm{PhD}^{1}$, Rashidat Abosede ADENEKAN BSc, $\mathrm{MSc}^{1}$, Ikeola Adejoke ADEOYE MBChB, MPH, FMCPH ${ }^{2}$, Akinkunmi Paul OKEKUNLE BSc, $\mathrm{MPH}, \mathrm{PhD}^{2,3 *}$

1. Department of Human Nutrition and Dietetics, Faculty of Public Health, College of Medicine, University of Ibadan, 200284 Ibadan, Nigeria.

2. Department of Epidemiology and Medical Statistics, Faculty of Public Health College of Medicine, University of Ibadan, 200284, Ibadan, Nigeria

3. The Postgraduate College, University of Ibadan, 200284, Ibadan Nigeria

Ethics Committee Approval: NHREC/05/01/2008a and UI/EC/14/0417

Source(s) of support: None

Acknowledgement: None

Conflict of interest: $\quad$ All authors declare they have no conflict of interest

Contribution Statement: FOS conceptualised and designed the study; RAA and APO did the literature search and review, RAA and FOS were responsible for data acquisition; APO was responsible for data analysis, statistical analysis and manuscript preparation, FOS, IAA and APO undertook the manuscript editing and review and FOS, RAA, IAA and APO were responsible for the definition of intellectual content, read and approved the final version of the manuscript for submission.

*All correspondence should be addressed to Okekunle AP (PhD); The Postgraduate College, University of Ibadan, 200284, Ibadan Nigeria. email: akinokekunle@gmail.com. Telephone: $+234-806-558-2920$. 


\section{Abstract}

Background: Studies exploring adolescent dietary patterns (DP) and nutritional status often focus on in-school adolescents with limited data on out-of-school adolescents.

Methods: We sampled 190 out-of-school adolescents on an apprenticeship in Agbowo community, Ibadan, Nigeria. Anthropometric measurements, weight $(\mathrm{kg})$, and height $(\mathrm{cm})$ were taken (to determine the height-for-age and body-mass-index-for-age z-scores) using the WHO AnthroPlus and WHO cut-off points to classify stunting and overweight/obesity. The frequency of food consumption was assessed using an 84-item food frequency questionnaire. The DP was extrapolated using principal component analysis. Bivariate and multivariate logistic regression analyses were used to assess the relationship between sociodemographic variables, anthropometric indices, and DP at $P<0.05$.

Results: Mean age was $16.9 \pm 1.9$ years, $61.6 \%$ were females and $58.4 \%$ had mothers who had at least secondary education. Overall, $12.1 \%$ were stunted and $9.5 \%$ were overweight/obese. Stunting was significantly more prevalent $(P=0.005)$ among males $(20.5 \%)$ than females $(6.8 \%)$. Males had higher odds for stunting [OR: $3.48(1.39,8.75) P=0.008$ ], and a lower odds of adhering to a 'healthy' DP; [OR: $0.42(0.22,0.80), P=0.009]$. Also, adolescents with mothers who had at least a secondary school education were less likely to adhere to an 'unhealthy' DP [0.26 $(0.11,0.59), P=0.001]$.

Conclusion: Targeted nutrition education is needed to address unhealthy dietary patterns, particularly among out-of-school adolescent boys.

Keywords: Nutritional status; Dietary patterns; Out of school; Adolescents; Apprentice.

\section{Introduction}

Adolescence is a critical stage in life (Ambrosini 2013) that is associated with both physiological and psychological changes (Aparicio et al. 2017) that not only impact nutritional wellbeing but also future risk of disease (Das et al. 2017, Hu et al. 2016). Over the years, the nutrition transition has progressively accelerated the incidence of noncommunicable diseases worldwide particularly among adolescents. The dual burden of undernutrition and over-nutrition among adolescent populations significantly impacts outcomes in adulthood ( $\mathrm{Hu}$ et al. 2016). While dietary patterns represent the diversity, magnitude and/or blend of foods in diets (Sánchez-Villegas and Martínez-Lapiscina 2018) when measured over a period of time, it is also a useful determinant in assessing food exposure, nutritional status, and health outcome(s) (Herzog and Cunningham-Rundles 2015, Badimon, Mendieta, and Vilahur 2015) in populations.

Given that nutrients are not consumed singly in diet (Okekunle et al. 2018), identifying dietary patterns across multiple foods is a useful epidemiological tool for understanding dietary exposure and implementing appropriate dietary interventions ( $\mathrm{Hu} 2002$ ). Various reports (Hu et al. 2016, Tayel, El-Sayed, and El-Sayed 2013) have discussed the implications of dietary patterns in adolescence as well as providing additional information on demographic correlate of these dietary patterns with health events in late adulthood.

However, most studies exploring dietary pattern adherence among adolescents focus on inschool adolescents with limited information among out-of-school adolescents, who are predominantly from low-resource backgrounds (Bashour 2004, Kotecha et al. 2013, Lehto et al. 2014, Lillie et al. 2019). About 250 million children and adolescents were out-of-school 
globally, with the highest out-of-school rates among adolescents from sub-Sahara Africa (UIS 2019). Studies have shown that out-of-school adolescents from sub-Sahara Africa are at elevated risk of adverse health outcomes ranging from non-communicable diseases, mental health problems, to disabilities of sexual and reproductive health (De Neve et al. 2020, De Neve et al. 2015, Viner et al. 2017).

Yet data on their nutritional status and dietary proclivities are generally limited. In addition, the significance of sociodemographic and lifestyle factors related to dietary patterns in this group has received little attention. Such information will significantly aid the understanding of their nutritional needs, providing insights into suitable strategies to improve their dietary habits and mitigate their burden of poor nutritional status. This study assessed nutritional status, dietary patterns, and associated factors among out-of-school adolescents in Ibadan, Southwestern Nigeria.

\section{Methods}

\section{Design}

The study was cross-sectional in design and carried out between February and December 2015 in Ibadan North Local Government Area of Oyo State, Southwest Nigeria.

The participants were out-of-school adolescents between 10 to 19 years. The sample size was estimated using a two-sided type I error of 5\% and a statistical power of $80 \%$ to detect an odds ratio of 1.5 based on the estimated proportion of out-of-school children determined by the Education Policy and Data Centre in the United States (EPDC 2013) and using the 2008 Nigeria Demographic Health Survey (National Population Commission - NPC/Nigeria and ICF Macro 2009). Using the formulae: $\left\{Z_{1-\alpha / 2}^{2} \times p(1-p)\right\} \div e^{2}$ (Charan and Biswas 2013); $Z=1.96$, the proportion of out-of-school adolescents in Southwest Nigeria $(p)=8 \%$ (0.08), and type I error $(e)=0.05$, we estimated a sample size of 108.5 . We included an additional $20 \%$ of the sample size to cater for the non-response rate and arrived at a final sample of 130 respondents.

Respondents were recruited through a four-stage sampling procedure. Ibadan North Local Government Area (LGA) was selected (by simple balloting) from five LGA in Ibadan municipality and we selected a political ward (ward 12) from among the twelve wards (each consisting of several communities) in Ibadan North LGA, also by simple balloting. Agbowo community was purposively selected out of the six communities in ward 12 because it was the only community with a complete list of registered tailor outlets (TO) at the time of the study. In Ibadan, tailoring is the major apprenticeship that engages both male and female outof-school adolescents; other apprentices are usually skewed towards either males only (carpentry, mechanics, bricklaying) or females only (hairdressing, bead-making, cosmetics). Agbowo has many features of an urban slum: overcrowding, unplanned housing, and lack of basic social amenities (Akinremi and Samuel 2015), and it has a projected population of 97,219 residents (Balogun 2019).

Out-of-school adolescents were then selected by systematic random sampling. First, we enumerated a total of 300 TOs that had out-of-school adolescents as apprentices $(N)$. A sampling interval $(i)$ was calculated by dividing $N$ with the proposed number of respondents $(n=130)$ for the study [i.e. $i=300 / 130=2.3$ ]. Second, the first TO was randomly selected (by simple balloting from the sampling frame of the enumerated TO), and every $2^{\text {nd }}$ TO was selected afterwards. At each TO selected, the proprietors and trainers of the TO were approached to approve the recruitment of out-of-school adolescents working in their organization for the study. Every eligible out-of-school adolescent (in each TO) who 
voluntarily provided written (and signed/thumbprint) informed consent was recruited and interviewed.

Adolescents who self-reported non-school attendance but were involved in a form of nonformal apprenticeship were recruited in the study if they met the following criteria; a) apparently healthy, b) aged 10-19 years c) residing within Ibadan for at least the last 2 years and c) currently not enrolled in, and/or dropped out any form of formal education in the last 3 years or more.

Trained personnel obtained information on sociodemographic and lifestyle characteristics through in-person interviews. Participants provided information on age at last birthday (in years), sex, marital status (single or married), school drop-out point, parents' education, the region of residence (peri-urban or urban), birth order, whether living with both parents or otherwise, household size, whether they frequently skipped meals during the day, preference for snacking while away from home and/or home-cooked meals.

Weight $( \pm 0.1 \mathrm{~kg})$ and height $( \pm 0.1 \mathrm{~cm})$ of participants (while wearing light-weight clothing without shoes) were assessed using a standard weighing scale and stadiometer, respectively, by qualified personnel using the WHO protocol (WHO 2020). Height for age (HA) and body mass index (BMI) for age z-scores were computed using WHO AnthroPlus. HA z-scores < 2SD was categorized as "stunted" (WHO 2007a) and BMI for age z-scores $>+1 \mathrm{SD}$ as overweight/obese (WHO 2007b) using the WHO cut-off points.

\section{Dietary pattern derivation}

Frequency of foods consumed in the last 7 days was assessed with an 84-item food frequency questionnaire containing eight food groups namely; cereals, root and tubers, legumes, vegetables, fruits, meat, fish, and snacks. Participants recalled the average weekly consumption frequency of food items with scores ranging from 0 - "never/occasionally to 7 "daily". Using the statistical procedure of principal component analysis (Okekunle et al. 2018), dietary patterns (DP) were determined from examining factor loadings of dietary intake. Using an eigenvalue $>1$, scree plot test and factor interpretability, two (2) factors were identified. Factor scores in each DP were ranked in increasing order and respondents were classified as having 'low' adherence to the DP if their factor score was $<50$ th percentile of the overall factor score in that DP. Also, respondents were classified as having 'high' adherence if they had a factor $\geq 50$ th percentile of the overall factor score in that DP.

\section{Statistical analysis}

The factor score of respondents in each DP was ranked from lowest to highest and a respondent was classified as having a 'low' adherence if their factor score was <50th percentile of all scores in that DP, otherwise 'high' adherence if factor score was $\geq 50$ th percentile. Sociodemographic characteristics and eating behaviour were evaluated across the distribution of stunting, overweight/obesity and DP using chi-square and t-tests for categorical and continuous variables, respectively. Logistic regression was used to estimate the multivariable-adjusted odds ratios (OR) and 95\% confidence intervals (CI) to identify socio-demographic factors associated with the risk of being (1) stunted or (2) overweight/obese and adherence to dietary patterns. All data analyses were carried out using IBM SPSS Statistics for Windows, version 21 (IBM Corp., Armonk, N.Y., USA). Statistical significance was defined as $P<0.05$. 


\section{Ethics Statement}

The Ethics Committee of the University of Ibadan and University College Hospital Ibadan Oyo State, Nigeria approved the study on 5th February 2015 with the registration number NHREC/05/01/2008a and UI/EC/14/0417.

\section{Results}

\section{Sociodemographic characteristics and eating behaviour}

In all, 190 out-of-school adolescents were recruited. Table 1 shows their characteristics, stratified by their nutritional status. Participants' mean age was $16.9 \pm 1.9$ years, most were $>14$ years $(86.3 \%)$, female $(61.6 \%)$, single $(94.7 \%)$, dropped out during primary school education $(8.9 \%)$ and living with both parents $(69.8 \%)$. The majority reported skipping meals $(90.5 \%)$ and snacking $(96.8 \%)$, and ate and/or prefered homemade meals $(87.8 \%)$. Stunting was more prevalent among males (20.5\%) than females $(6.8 \%) ; \quad(P=0.005)$. Overweight/obesity was more common in females $(11.1 \%)$ compared to males $(6.8 \%)$. Sociodemographic factors had no significant relationship with BMI-for-age.

\section{Dietary patterns}

Two dietary patterns (DP) amounting to $56.6 \%$ of the total variance in the diet were identified using principal component analysis. They were named 'healthy' and 'unhealthy' and their respective factor loadings are presented in Table 2. The first DP referred to as 'healthy' contributed $33.9 \%$ of the variance and consisted of food sources such as cereals, roots and tubers, legumes, vegetables, fruits, meat and fish and snacks (positive scoring coefficients). The second DP 'unhealthy' explained $22.7 \%$ of the total variance and consisted of food sources such as root, tubers and legumes (positive scoring coefficients), but had negative scoring coefficients on fruits, meat and fish as well as very low points of vegetables.

Table 3 represents the characteristics of out-of-school adolescents by the identified dietary patterns in the study. The proportion of adolescents with "healthy" DP, was significantly higher $(P=0.002)$ among adolescents who dropped out during secondary school education (53.2\%), compared to those who dropped out during primary school education $(17.6 \%)$. Similarly, the proportion of adolescents who adhered to a healthy DP was higher among adolescents whose parents had at least secondary school education compared to adolescents with parents of low educational status $(P=0.017)$.

The adjusted OR and 95\% CI of the factors associated with adherence to "healthy" and "unhealthy" DP by socio-demographic characteristics are shown in Table 4. Males were less than half as likely as females to adhere to the "healthy" DP [OR $0.42 ; 95 \%$ CI: $0.22-0.80$, $P=0.009]$. Also, higher maternal education was associated with lower odds of adherence to unhealthy DP [OR 0.26 ; 95\%CI: $0.11-0.59, P=0.001$ ]. Finally, males were more than three times as likely to be stunted as females [OR: $3.48 ; 95 \%$ CI: $1.39-8.75, P=0.008$ ].

\section{Discussion}

To the best of our knowledge, our report presents unique information on nutritional status and dietary patterns among out-of-school adolescents in Nigeria. Stunting was more prevalent among males, and overweight/obesity more among females. Two dietary patterns were identified: "healthy" and "unhealthy". Adolescents who had parents with a higher education adhered more often to the "healthy" dietary patterns after adjusting for sociodemographic confounders. 
In tandem with our findings, male adolescents were significantly more stunted than females in other samples of adolescents from sub-Saharan Africa (Lillie et al. 2019, Akombi et al. 2017). In contrast to our findings, a study among adolescents in Brazil found that males were likely to be obese than females (Araújo et al. 2010).

The 'healthy' and 'unhealthy' patterns in our study are analogous to consumption patterns of 'healthy' and 'processed' foods reported among adolescents in Spain (Bodega et al. 2019). Likewise, our 'healthy' pattern is comparable to that reported among adolescents in Tehran(Akbari-Sedigh et al. 2019) with positive scoring factor for; legumes, fruits, vegetables, low-fat dairy, etc and negative scoring factor for; high-fat dairy, fast foods, sugarsweetened beverages and refined grains. Additionally, the dietary patterns in our study were similar to the 'least' and 'most' diverse patterns derived in another report among adolescents in Bangladesh (Thorne-Lyman et al. 2019) characterised by low (except potatoes) and high consumption of all food items respectively. In the African setting, the dietary pattern in our study was analogous to the traditional and sweet-tooth patterns reported among schooling adolescents in Ghana (Abizari and Ali 2019).

The two identified dietary patterns are typical of adolescents in African settings (Abizari and Ali 2019) and comparable to adolescents from other regions (Bodega et al. 2019, AkbariSedigh et al. 2019, Thorne-Lyman et al. 2019). Our report on adherence to healthy dietary patterns compares to that of Bodega et al (Bodega et al. 2019) in Spain and Akbari-Sedigh and others (Akbari-Sedigh et al. 2019) in Tehran. In their reports, female adolescents adhered to the 'healthy' pattern but not the 'processed' or 'unhealthy' patterns. Also, more males adhered to the most diverse and traditional dietary patterns among adolescents in Ghana (Abizari and Ali 2019) and Bangladesh (Thorne-Lyman et al.) respectively.

A country-wide, community-based cross-sectional study among adolescents in Germany also revealed differences in dietary patterns between male and female adolescents (Richter et al. 2012). In that study, the 'western' pattern was predominant among male adolescents, but the 'healthy' pattern was more common among female adolescents. Also, the factor loading of foods in the healthy pattern among female adolescents differed widely from that of male adolescents.

It could imply that food choices/preferences of male adolescents are quite limited and perhaps may be explained by cultural dimensions. That is, the early exposure of female adolescents to culinary and home-management skills in preparation for care-giving roles in the household (Association 2020) perhaps potentially offers them leverage in making healthy food choices of diversity than their male counterparts. Also, it has been shown that as adolescents grow older they are prone to adopting 'junk food' as they spend more time outside the home (Kourlaba et al. 2009). It is not unlikely that this behaviour is aggravated among male adolescents. A longitudinal report among adolescents in the United States of America (Cutler et al. 2008) has similarly observed a slight tilt in the preference for fast food among males during adolescence. Another study among adolescent in Nigeria revealed no difference by gender in snack consumption (Olawuyi et al. 2020). However, the respondents in that report were university students, as against the out-of-school population in our study. In addition, that study compared a direct assessment of snacks consumption only, but we applied principal component analysis to derive dietary patterns from the whole diet. Taken together, the role of gender in dietary preferences needs further exploration. 
Table 1: Characteristics of out-of-school adolescents in the study stratified by their nutritional status

\begin{tabular}{|c|c|c|c|c|c|c|c|c|}
\hline \multirow[t]{2}{*}{ Characteristic } & & \multirow{2}{*}{$\begin{array}{c}\text { All } \\
\text { participants }\end{array}$} & \multicolumn{3}{|c|}{ Height-for-age } & \multicolumn{3}{|c|}{ BMI-for-age } \\
\hline & & & Non-Stunted & Stunted & $P$ & Normal weight & Overweight/Obese & $P$ \\
\hline \multirow[t]{3}{*}{ Age $(y)$} & & $16.92 \pm 1.99$ & $16.95 \pm 2.04$ & $16.70 \pm 1.60$ & 0.504 & $16.91 \pm 2.00$ & $17.00 \pm 1.87$ & 0.844 \\
\hline & $10-14$ & $26(13.7)$ & $25(96.2)$ & $01(3.8)$ & 0.165 & $24(92.3)$ & $02(7.7)$ & 0.738 \\
\hline & $15-19$ & $164(86.3)$ & $142(86.60$ & $22(13.4)$ & & $148(90.2)$ & $16(9.8)$ & \\
\hline \multirow[t]{2}{*}{ Sex } & Female & $117(61.6)$ & $109(93.2)$ & $08(6.8)$ & 0.005 & $104(88.9)$ & $13(11.1)$ & 0.329 \\
\hline & Male & $73(38.4)$ & $58(79.5)$ & $15(20.5)$ & & $68(93.2)$ & $05(6.8)$ & \\
\hline \multirow[t]{2}{*}{ Marital Status } & Single & $178(94.7)$ & $155(87.1)$ & $23(12.9)$ & 0.225 & $161(90.4)$ & $17(9.6)$ & 0.963 \\
\hline & Married & $10(5.3)$ & $10(100.0)$ & $00(0.0)$ & & $09(90.0)$ & $01(10.0)$ & \\
\hline \multirow[t]{2}{*}{ Ethnicity } & Yoruba & $181(95.8)$ & $159(87.8)$ & $22(12.2)$ & 0.977 & $164(90.6)$ & $17(9.4)$ & 0.769 \\
\hline & Others & $08(4.2)$ & $07(87.5)$ & $01(12.5)$ & & $07(87.5)$ & $01(12.5)$ & \\
\hline \multirow[t]{2}{*}{ Education $^{*}$} & Primary & $17(8.9)$ & $14(82.4)$ & $03(17.6)$ & 0.463 & $14(82.4)$ & $03(17.6)$ & 0.228 \\
\hline & Secondary & $173(91.1)$ & $153(88.4)$ & $20(11.6)$ & & $158(91.3)$ & $15(8.7)$ & \\
\hline \multirow[t]{2}{*}{ Fathers' Education } & $\leq$ Primary & $53(28.0)$ & $46(86.8)$ & $07(13.2)$ & 0.785 & $47(88.7)$ & $06(11.3)$ & 0.599 \\
\hline & $\geq$ Secondary & $136(72.0)$ & $120(88.2)$ & $16(11.8)$ & & $124(91.2)$ & $12(8.8)$ & \\
\hline \multirow[t]{2}{*}{ Mother's Education } & $\leq$ Primary & $79(41.6)$ & $67(84.8)$ & $12(15.2)$ & 0.271 & $71(89.9)$ & $08(10.1)$ & 0.795 \\
\hline & $\geq$ Secondary & $111(58.4)$ & $100(90.1)$ & $11(9.9)$ & & $101(91.0)$ & $10(9.0)$ & \\
\hline \multirow[t]{2}{*}{ Residence } & Peri urban & $57(30.2)$ & $49(86.0)$ & $08(14.0)$ & 0.606 & $51(89.5)$ & $06(10.5)$ & 0.758 \\
\hline & Urban & $132(69.8)$ & $117(88.6)$ & $15(11.4)$ & & $120(90.9)$ & $12(9.1)$ & \\
\hline \multirow[t]{2}{*}{ First Birth order } & No & $145(77.1)$ & $126(86.9)$ & $19(13.1)$ & 0.272 & $134(92.4)$ & $11(7.6)$ & 0.201 \\
\hline & Yes & $43(22.9)$ & $40(93.0)$ & $03(7.0)$ & & $37(86.0)$ & $06(14.0)$ & \\
\hline \multirow[t]{2}{*}{ Living with Both Parents } & No & $57(30.2)$ & $52(91.2)$ & $05(8.8)$ & 0.348 & $52(91.2)$ & $05(8.8)$ & 0.817 \\
\hline & Yes & $132(69.8)$ & $114(86.4)$ & $18(13.6)$ & & $119(90.2)$ & $13(9.8)$ & \\
\hline \multirow[t]{2}{*}{ Household Size } & $\leq 5$ & $99(52.1)$ & $89(89.9)$ & $10(10.1)$ & 0.377 & $90(90.9)$ & $09(9.1)$ & 0.851 \\
\hline & $>5$ & $91(47.9)$ & $78(85.7)$ & $13(14.3)$ & & $82(90.1)$ & 09 (9.9) & \\
\hline \multirow[t]{2}{*}{ Meal Skipping } & No & $18(9.5)$ & $16(88.9)$ & $02(11.1)$ & 0.892 & $16(88.9)$ & $02(11.1)$ & 0.803 \\
\hline & Yes & $172(90.5)$ & $151(87.8)$ & $21(12.2)$ & & $156(90.7)$ & $16(9.3)$ & \\
\hline \multirow[t]{2}{*}{ Snacking } & No & $06(3.2)$ & $06(100.0)$ & $00(0.0)$ & 0.356 & $05(83.3)$ & $01(16.7)$ & 0.541 \\
\hline & Yes & $184(96.8)$ & $161(87.5)$ & $23(12.5)$ & & $167(90.8)$ & $17(9.2)$ & \\
\hline \multirow[t]{2}{*}{ Home cook meals } & No & $23(12.2)$ & $22(95.7)$ & $01(4.3)$ & 0.221 & $145(90.6)$ & $15(9.4)$ & 0.742 \\
\hline & Yes & $166(87.8)$ & $144(86.7)$ & $22(13.3)$ & & $25(92.6)$ & $02(7.4)$ & \\
\hline
\end{tabular}

BMI - body mass index; * - level of education at which adolescent dropped of school 
Table 2: Factor loadings for two dietary patterns for the study participants

\begin{tabular}{lcc}
\hline Food groups & \multicolumn{2}{c}{ Dietary Patterns (Factor Loadings) } \\
& Healthy (1) & Unhealthy (2) \\
\hline Cereals & $\mathbf{0 . 7 8 1}$ & 0.082 \\
Roots and Tubers & $\mathbf{0 . 5 5 3}$ & $\mathbf{0 . 5 8 4}$ \\
Legumes & $\mathbf{0 . 4 2 3}$ & $\mathbf{0 . 7 2 3}$ \\
Vegetables & $\mathbf{0 . 6 0 2}$ & 0.080 \\
Fruits & $\mathbf{0 . 4 3 4}$ & $\mathbf{- 0 . 6 4 5}$ \\
Meat and Fish & $\mathbf{0 . 6 4 4}$ & $\mathbf{- 0 . 4 8 5}$ \\
Snacks & $\mathbf{0 . 5 5 8}$ & -0.297 \\
\%Variance of explained dietary pattern & 33.881 & 22.705 \\
\% Cumulative variance & 56.586 & 0.369 \\
Kaiser-Meyer-Olkin (KMO) Measure of Sampling Adequacy & 0.685 & 0.624 \\
Bartlett's test of sphericity & 245.645 & 0.400 \\
\hline
\end{tabular}

Factor loading of absolute values $\geq \mathbf{0 . 4 0}$ was considered inclusion in each dietary pattern 
Table 3: Characteristics of out-of-school adolescents stratified by the identified dietary patterns in the study

\begin{tabular}{|c|c|c|c|c|c|c|c|c|}
\hline \multirow[t]{2}{*}{ Characteristic } & & \multirow[b]{2}{*}{ All participants } & \multicolumn{3}{|c|}{ Healthy Dietary Pattern } & \multicolumn{3}{|c|}{ Unhealthy Dietary Pattern } \\
\hline & & & Low & High & $P$ & Low & High & $P$ \\
\hline \multirow[t]{3}{*}{ Age $(y)$} & & $16.92 \pm 1.99$ & $16.79 \pm 2.01$ & $17.04 \pm 1.96$ & 0.383 & $17.23 \pm 1.74$ & $16.60 \pm 2.17$ & 0.028 \\
\hline & $10-14$ & $26(13.7)$ & $15(57.7)$ & $11(42.3)$ & 0.398 & $10(38.5)$ & $16(61.5)$ & 0.205 \\
\hline & $15-19$ & $164(86.3)$ & $80(48.8)$ & $84(51.2)$ & & $85(51.8)$ & $79(48.2)$ & \\
\hline \multirow[t]{2}{*}{ Sex } & Female & $117(61.6)$ & $48(41.0)$ & $69(59.0)$ & 0.002 & $63(53.8)$ & $54(46.2)$ & 0.179 \\
\hline & Male & $73(38.4)$ & $47(64.4)$ & $26(35.6)$ & & $32(43.8)$ & $41(56.2)$ & \\
\hline \multirow[t]{2}{*}{ Marital Status } & Single & $178(94.7)$ & $88(49.4)$ & $90(50.6)$ & 0.972 & $88(49.4)$ & $90(50.6)$ & 0.206 \\
\hline & Married & $10(5.3)$ & $05(50.0)$ & $05(50.0)$ & & $07(70.0)$ & $03(30.0)$ & \\
\hline \multirow[t]{2}{*}{ Ethnicity } & Yoruba & $181(95.8)$ & $92(50.8)$ & $89(49.2)$ & 0.153 & $92(50.8)$ & $89(49.2)$ & 0.461 \\
\hline & Others & $08(4.2)$ & $02(25.0)$ & $06(75.0)$ & & $03(37.5)$ & $05(62.5)$ & \\
\hline \multirow{2}{*}{ Education* } & $\leq$ Primary & $17(8.9)$ & $14(82.4)$ & $03(17.6)$ & 0.005 & $06(35.3)$ & $11(64.7)$ & 0.204 \\
\hline & $\geq$ Secondary & $173(91.1)$ & $81(46.8)$ & $92(53.2)$ & & $89(51.4)$ & $84(48.6)$ & \\
\hline \multirow{2}{*}{ Fathers' Education } & $\leq$ Primary & $53(28.0)$ & $34(64.2)$ & $19(35.8)$ & 0.017 & $20(37.7)$ & $33(62.3)$ & 0.032 \\
\hline & $\geq$ Secondary & $136(72.0)$ & $61(44.9)$ & $75(55.1)$ & & $75(55.1)$ & $61(44.9)$ & \\
\hline \multirow[t]{2}{*}{ Mother's Education } & $\leq$ Primary & 79 (41.6) & $49(62.0)$ & $30(38.0)$ & 0.005 & $26(32.9)$ & $53(67.1)$ & 0.000 \\
\hline & $\geq$ Secondary & $111(58.4)$ & $46(41.4)$ & $65(58.6)$ & & $69(62.2)$ & $42(37.8)$ & \\
\hline \multirow[t]{2}{*}{ Residence } & Peri urban & $57(30.2)$ & $31(54.4)$ & $26(45.6)$ & 0.401 & $22(38.6)$ & $35(61.4)$ & 0.044 \\
\hline & Urban & $132(69.8)$ & $63(47.7)$ & $69(52.3)$ & & $72(54.5)$ & $60(45.5)$ & \\
\hline \multirow[t]{2}{*}{ First Birth order } & No & $145(77.1)$ & $77(53.1)$ & $68(46.9)$ & 0.067 & $73(50.3)$ & $72(49.7)$ & 0.862 \\
\hline & Yes & $43(22.9)$ & $16(37.2)$ & $27(62.8)$ & & $21(48.8)$ & $22(51.2)$ & \\
\hline \multirow[t]{2}{*}{ Living with Both Parents } & No & $57(30.2)$ & $31(54.4)$ & $26(45.6)$ & 0.456 & $32(56.1)$ & $25(43.9)$ & 0.288 \\
\hline & Yes & $132(69.8)$ & 64 (48.5) & $68(51.5)$ & & $63(47.7)$ & $69(52.3)$ & \\
\hline \multirow{2}{*}{ Household Size } & $\leq 5$ & $99(52.1)$ & $48(48.5)$ & $51(51.5)$ & 0.663 & $43(43.4)$ & $56(56.6)$ & 0.059 \\
\hline & $>5$ & $91(47.9)$ & 47 (51.6) & $44(48.4)$ & & $52(57.1)$ & 39 (42.9) & \\
\hline \multirow{2}{*}{ Meal Skipping } & No & $18(9.5)$ & $06(33.3)$ & $12(66.7)$ & 0.137 & $11(61.1)$ & 07 (38.9) & 0.322 \\
\hline & Yes & $172(90.5)$ & 89 (51.7) & $83(48.3)$ & & $84(48.8)$ & $88(51.2)$ & \\
\hline \multirow[t]{2}{*}{ Snacking } & No & $06(3.2)$ & $03(50.0)$ & $03(50.0)$ & 1.000 & $04(66.7)$ & $02(33.3)$ & 0.407 \\
\hline & Yes & $184(96.8)$ & $92(50.0)$ & $92(50.0)$ & & $91(49.5)$ & $93(50.5)$ & \\
\hline \multirow[t]{2}{*}{ Home cook meals } & No & $23(12.2)$ & $06(26.1)$ & $17(73.9)$ & 0.013 & $15(65.2)$ & 08 (34.8) & 0.126 \\
\hline & Yes & $166(87.8)$ & 89 (53.6) & 77 (46.4) & & $80(48.2)$ & $86(51.8)$ & \\
\hline \multirow[t]{2}{*}{ Stunting } & No & $167(87.9)$ & $80(47.9)$ & $87(52.1)$ & 0.120 & $86(51.5)$ & $81(48.5)$ & 0.266 \\
\hline & Yes & $23(12.1)$ & $15(65.2)$ & $08(34.8)$ & & $09(39.1)$ & $14(60.9)$ & \\
\hline \multirow[t]{2}{*}{ BMI for age } & Normal weight & $172(90.5)$ & $88(51.2)$ & $84(48.8)$ & 0.322 & $86(50.0)$ & $86(50.0)$ & 1.000 \\
\hline & Overweight/Obese & $18(9.5)$ & $07(38.9)$ & $11(61.1)$ & & $09(50.0)$ & $09(50.0)$ & \\
\hline
\end{tabular}

BMI - body mass index; *level of education at which adolescent dropped out of school 
Table 4: Adjusted odds ratio and $95 \%$ confidence interval for risk of malnutrition and adherence to dietary patterns

\begin{tabular}{|c|c|c|c|c|c|c|c|c|}
\hline \multirow[b]{3}{*}{ Characteristic } & \multicolumn{4}{|c|}{ Nutritional Status } & \multicolumn{4}{|c|}{ Dietary Pattern } \\
\hline & Height for Age & & BMI for Age & & Healthy & & Unhealthy & \\
\hline & Odds ratio & $P$ & Odds ratio & $P$ & Odds ratio & $P$ & Odds ratio & $P$ \\
\hline Age (y) & $0.98(0.79,1.21)$ & 0.829 & $1.01(0.78,1.30)$ & 0.945 & $0.99(0.84,1.17)$ & 0.921 & $0.87(0.74,1.02)$ & 0.093 \\
\hline Sex (Male) & $3.48(1.39,8.75)$ & 0.008 & $0.59(0.20,1.74)$ & 0.341 & $0.42(0.22,0.80)$ & 0.009 & $1.01(0.53,1.94)$ & 0.974 \\
\hline Education* ( $\geq$ Secondary) & & & & & $3.40(0.84,13.66)$ & 0.085 & $1.19(0.35,4.03)$ & 0.775 \\
\hline Fathers' Education ( $\geq$ Secondary) & & & & & $1.31(0.54,3.21)$ & 0.555 & $1.18(0.47,2.96)$ & 0.729 \\
\hline Mothers' Education ( $\geq$ Secondary) & & & & & $1.45(0.66,3.20)$ & 0.353 & $0.26(0.11,0.59)$ & 0.001 \\
\hline Residence (Urban) & & & & & $1.16(0.59,2.29)$ & 0.666 & $0.55(0.28,1.10)$ & 0.090 \\
\hline
\end{tabular}


Findings that parents' and particularly mothers' education was inversely related to adherence to the unhealthy dietary pattern are in line with other studies (Lehto et al. 2014, Finger et al. 2015, Desbouys et al. 2019, Vereecken and Maes 2010, Ambrosini et al. 2009). Education is an important social determinant for positive health outcomes because it increases knowledge, health literacy, and improved healthy choices. Education is a perceived reflection of the capacity to juxtapose nutritional information for appropriate behaviour. Adolescents from less-educated households are prone to eating smaller and larger amounts of healthy and unhealthy foods respectively (Desbouys et al. 2019). First, nutrition knowledge has been established to produce better outcomes in mothers with a higher level of education (Vereecken and Maes 2010). Second, higher-level parental education has been linked to lower intakes of energy-dense foods in addition to higher intakes of fruits and vegetables among adolescents (Finger et al. 2015). Also, in a survey among adolescents in Australia, preference for a healthy pattern among children was linked to higher mother's education (Ambrosini et al. 2009).

These observations suggest an association can be identified between the education of parent/guardian and food choice of the adolescent. That is, where parents (particularly mothers) of the adolescent are well educated and informed, it is expected they will be able to educate and guide their children/adolescents on good dietary habit. In tandem with this observation, parental education positively correlated with vegetable and fruit intake among children from European countries (Lehto et al. 2014). Because out-of-school adolescents are still dependent on their parents and likely to spend some time away from school, strong familial influence (particularly that of the mother) on their dietary attitude is plausible. Generally, the older the adolescent, the less likely the familial parental influence on their dietary habits. In this study, a higher proportion of adolescent who dropped out during their secondary school education adhered to the 'healthy' dietary pattern than those who dropped out during primary school education. Early introduction of nutrition education in adolescence (before other external influences) is not only imperative but also critical in shaping dietary behaviour in later adulthood. In our sample, such education may have been effectively provided by the home, whereas in other studies there is evidence to show that formal education has been reported to be a strong predictor of dietary behaviour among adolescents (Desbouys et al. 2019).

There are some limitations worth mentioning. Total energy intake was not measured, and the outcomes are founded on the frequency of food consumption only. This might disguise variances of total caloric exposure and actual portion sizes of food consumed. The crosssectional design limited a deeper probe into causal factors associated with the outcome variables in this study. Also, the recruitment of respondents was limited to apprentices from tailoring outfits only, for reasons mentioned above.

\section{Conclusions}

This study probed nutritional status (through anthropometric indices), dietary patterns, and associated factors among out-of-school adolescents in Ibadan, Southwestern Nigeria. This was done against a backdrop of scarce reports on this population compared to in-school adolescents. The results found that males in general not only had higher undernutrition indices but they were also more likely to choose an unhealthy dietary pattern compared to females. Also, more females presented slightly higher overnutrition indices. A probe of associated factors also revealed that the education of mothers influenced the choice for a "healthy" dietary pattern. Our findings suggest dietary intake may be influenced beyond the usual pathways of appetite or hunger and rely on the characteristic of the guardian/parent and 
by extension the kind of food environment in which the out-of-school adolescent lives. A further probe of food environments within Ibadan metropolis is hereby recommended to understand food choices and drivers of healthier diets.

\section{References}

Abizari, Abdul-Razak, and Zakari Ali. 2019. "Dietary patterns and associated factors of schooling Ghanaian adolescents." Journal of Health, Population and Nutrition 38 (1):5. doi: 10.1186/s41043-019-0162-8.

Akbari-Sedigh, Assa, Golaleh Asghari, Emad Yuzbashian, Pooneh Dehghan, Hossein Imani, and Parvin Mirmiran. 2019. "Association of dietary pattern with carotid intima media thickness among children with overweight or obesity." Diabetology \& Metabolic Syndrome 11 (1):77. doi: 10.1186/s13098-019-0472-4.

Akinremi, Zainab Olanike, and Folake Olukemi Samuel. 2015. "Knowledge and Attitude of Exclusive Breastfeeding among Hairdresser Apprentices in Ibadan, Nigeria." Journal of Advances in Medicine and Medical Research 5 (3):376-385. doi: https://doi.org/10.9734/BJMMR/2015/12822.

Akombi, J. Blessing, E. Kingsley Agho, J. John Hall, Nidhi Wali, M. N. Andre Renzaho, and Dafna Merom. 2017. "Stunting, Wasting and Underweight in Sub-Saharan Africa: A Systematic Review." International Journal of Environmental Research and Public Health 14 (8). doi: 10.3390/ijerph14080863.

Ambrosini, Gina L. 2013. "Childhood dietary patterns and later obesity: a review of the evidence." Proceedings of the Nutrition Society 73 (1):137-146. doi: 10.1017/S0029665113003765.

Ambrosini, Gina L., Wendy H. Oddy, Monique Robinson, Therese A. O'Sullivan, Beth P. Hands, Nick H. de Klerk, Sven R. Silburn, Stephen R. Zubrick, Garth E. Kendall, Fiona J. Stanley, and Lawrence J. Beilin. 2009. "Adolescent dietary patterns are associated with lifestyle and family psychosocial factors." Public health nutrition 12 (10):1807-1815. doi: 10.1017/S1368980008004618.

Aparicio, Estefania, Josefa Canals, Núria Voltas, Anna Valenzano, and Victoria Arija. 2017. "Emotional Symptoms and Dietary Patterns in Early Adolescence: A School-Based Follow-up Study." Journal of Nutrition Education and Behavior 49 (5):405-414.e1. doi: 10.1016/j.jneb.2017.01.015.

Araújo, Cora Luiza, Samuel C. Dumith, Ana M. B. Menezes, Pedro C. Hallal, Maria de Fátima A. Vieira, Samanta W. Madruga, and Cesar G. Victora. 2010. "Nutritional status of adolescents: the 11year follow-up of the 1993 Pelotas (Brazil) birth cohort study." Cadernos de saude publica 26 (10):1895-1903. doi: 10.1590/s0102-311x2010001000005.

Association, American Psychological. 2020. "Who Are Family Caregivers?", accessed 18/01. https://www.apa.org/pi/about/publications/caregivers/faq/statistics.

Badimon, Lina, Guiomar Mendieta, and Gemma Vilahur. 2015. "Chapter 34 - Gene Expression, Atherogenesis, and the Mediterranean Diet." In The Mediterranean Diet, edited by Victor R. Preedy and Ronald Ross Watson, 367-378. San Diego: Academic Press.

Balogun, Femi A. 2019. "Rapid Urbanization and Environmental Poverty in Residential Areas of Agbowo, Ibadan, Nigeria." IOSR Journal Of Humanities And Social Science (IOSR-JHSS) 24 (4 (1)):51-57. doi: 10.9790/0837-2404015157.

Bashour, H. N. 2004. "Survey of dietary habits of in-school adolescents in Damascus, Syrian Arab Republic." East Mediterr Health J 10 (6):853-62.

Bodega, Patricia, Juan Miguel Fernández-Alvira, Gloria Santos-Beneit, Amaya de Cos-Gandoy, Rodrigo Fernández-Jiménez, Luis Alberto Moreno, Mercedes de Miguel, Vanesa Carral, Xavier Orrit, Isabel Carvajal, Carolina E. Storniolo, Anna Tresserra-Rimbau, Mónica Doménech, Ramón Estruch, Rosa María Lamuela-Raventós, and Valentín Fuster. 2019. 
"Dietary Patterns and Cardiovascular Risk Factors in Spanish Adolescents: A Cross-Sectional Analysis of the SI! Program for Health Promotion in Secondary Schools." Nutrients 11 (10):2297.

Charan, Jaykaran, and Tamoghna Biswas. 2013. "How to calculate sample size for different study designs in medical research?" Indian journal of psychological medicine 35 (2):121-126. doi: 10.4103/0253-7176.116232.

Cutler, Gretchen J., Andrew Flood, Peter Hannan, and Dianne Neumark-Sztainer. 2008. "Major Patterns of Dietary Intake in Adolescents and Their Stability over Time." The Journal of Nutrition 139 (2):323-328. doi: 10.3945/jn.108.090928.

Das, Jai K., Rehana A. Salam, Kent L. Thornburg, Andrew M. Prentice, Susan Campisi, Zohra S. Lassi, Berthold Koletzko, and Zulfiqar A. Bhutta. 2017. "Nutrition in adolescents: physiology, metabolism, and nutritional needs." Annals of the New York Academy of Sciences 1393 (1):21-33. doi: 10.1111/nyas.13330.

De Neve, Jan-Walter, Günther Fink, S. V. Subramanian, Sikhulile Moyo, and Jacob Bor. 2015. "Length of secondary schooling and risk of HIV infection in Botswana: evidence from a natural experiment." The Lancet. Global health 3 (8):e470-e477. doi: 10.1016/S2214109X(15)00087-X.

De Neve, Jan-Walter, Omar Karlsson, Chelsey R. Canavan, Angela Chukwu, Seth Adu-Afarwuah, Justine Bukenya, Anne Marie Darling, Guy Harling, Mosa Moshabela, Japhet Killewo, Günther Fink, Wafaie W. Fawzi, and Yemane Berhane. 2020. "Are out-of-school adolescents at higher risk of adverse health outcomes? Evidence from 9 diverse settings in sub-Saharan Africa." Tropical Medicine \& International Health 25 (1):70-80. doi: https://doi.org/10.1111/tmi.13328.

Desbouys, Lucille, Karin De Ridder, Manon Rouche, and Katia Castetbon. 2019. "Food Consumption in Adolescents and Young Adults: Age-Specific Socio-Economic and Cultural Disparities (Belgian Food Consumption Survey 2014)." Nutrients 11 (7):1520.

EPDC. 2013. "Nigeria Out of School Profile." FHI 360 - Education Policy and Data Center Washington, US, accessed 2015. https://www.epdc.org/node/4441.html.

Finger, Jonas D., Gianni Varnaccia, Thorkild Tylleskär, Thomas Lampert, and Gert B. M. Mensink. 2015. "Dietary behaviour and parental socioeconomic position among adolescents: the German Health Interview and Examination Survey for Children and Adolescents 2003-2006 (KiGGS)." BMC Public Health 15 (1):498. doi: 10.1186/s12889-015-1830-2.

Herzog, Ronit, and Susanna Cunningham-Rundles. 2015. "Chapter 74 - Malnutrition, Immunodeficiency, and Mucosal Infection." In Mucosal Immunology (Fourth Edition), edited by Jiri Mestecky, Warren Strober, Michael W. Russell, Brian L. Kelsall, Hilde Cheroutre and Bart N. Lambrecht, 1461-1479. Boston: Academic Press.

Hu, F. B. 2002. "Dietary pattern analysis: a new direction in nutritional epidemiology." Curr Opin Lipidol 13 (1):3-9.

Hu, Tian, David R. Jacobs, Jr., Nicole I. Larson, Gretchen J. Cutler, Melissa N. Laska, and Dianne Neumark-Sztainer. 2016. "Higher Diet Quality in Adolescence and Dietary Improvements Are Related to Less Weight Gain During the Transition From Adolescence to Adulthood." The Journal of Pediatrics 178:188-193.e3. doi: 10.1016/j.jpeds.2016.08.026.

Kotecha, P. V., S. V. Patel, R. K. Baxi, V. S. Mazumdar, M. Shobha, K. G. Mehta, D. Mansi, and M. Ekta. 2013. "Dietary pattern of schoolgoing adolescents in urban Baroda, India." J Health Popul Nutr 31 (4):490-6. doi: 10.3329/jhpn.v31i4.20047.

Kourlaba, Georgia, Demosthenes B. Panagiotakos, Kostas Mihas, Alevizos Alevizos, Kostas Marayiannis, Anargiros Mariolis, and Yannis Tountas. 2009. "Dietary patterns in relation to socio-economic and lifestyle characteristics among Greek adolescents: a multivariate analysis." Public Health Nutrition 12 (9):1366-1372. doi: 10.1017/S1368980008004060.

Lehto, Elviira, Carola Ray, Saskia te Velde, Stefka Petrova, Vesselka Duleva, Michael Krawinkel, Isabel Behrendt, Angeliki Papadaki, Asa Kristjansdottir, Inga Thorsdottir, Agneta Yngve, Nanna Lien, 
Christel Lynch, Bettina Ehrenblad, Maria Daniel Vaz de Almeida, Cirila Hlastan Ribic, Irena Simčic, and Eva Roos. 2014. "Mediation of parental educational level on fruit and vegetable intake among schoolchildren in ten European countries." Public Health Nutrition 18 (1):8999. doi: $10.1017 /$ S136898001300339X.

Lillie, Margaret, Isaac Lema, Sylvia Kaaya, Dori Steinberg, and Joy Noel Baumgartner. 2019.

"Nutritional status among young adolescents attending primary school in Tanzania: contributions of mid-upper arm circumference (MUAC) for adolescent assessment." BMC Public Health 19 (1):1582. doi: 10.1186/s12889-019-7897-4.

National Population Commission - NPC/Nigeria, and ICF Macro. 2009. Nigeria Demographic and Health Survey 2008. Abuja, Nigeria: NPC/Nigeria and ICF Macro.

Okekunle, Akinkunmi Paul, Xiaoyan Wu, Wei Duan, Rennan Feng, Ying Li, and Changhao Sun. 2018. "Dietary Intakes of Branched-Chained Amino Acid and Risk for Type 2 Diabetes in Adults: The Harbin Cohort Study on Diet, Nutrition and Chronic Non-Communicable Diseases Study." Canadian Journal of Diabetes 42 (5):484-492.e7. doi: 10.1016/j.jcjd.2017.12.003.

Olawuyi, Yetunde Olukemi, Oluyinka Oroniran, Grace Fadupin, and Pearl Takpatore. 2020. "Snacks and Beverage Consumption pattern of Adolescents and Young Adults." World Nutrition 11 (1):42-57. doi: https://worldnutritionjournal.org/index.php/wn/article/view/686.

Richter, Almut, Christin Heidemann, Matthias B. Schulze, Jutta Roosen, Silke Thiele, and Gert B. M. Mensink. 2012. "Dietary patterns of adolescents in Germany - Associations with nutrient intake and other health related lifestyle characteristics." BMC Pediatrics 12 (1):35. doi: 10.1186/1471-2431-12-35.

Sánchez-Villegas, Almudena, and Elena H. Martínez-Lapiscina. 2018. "Chapter 11 - A Healthy Diet for Your Heart and Your Brain." In The Prevention of Cardiovascular Disease Through the Mediterranean Diet, edited by Almudena Sánchez-Villegas and Ana Sánchez-Tainta, 169-197. Academic Press.

Tayel, Dalia I., Noha A. El-Sayed, and Nawal A. El-Sayed. 2013. "Dietary pattern and blood pressure levels of adolescents in Sohag, Egypt." The Journal Of The Egyptian Public Health Association 88 (2):97-103. doi: 10.1097/01.EPX.0000430963.78876.0a.

Thorne-Lyman, Andrew L., Saijuddin Shaikh, Sucheta Mehra, Lee S.F. Wu, Hasmot Ali, Kelsey Alland, Kerry J. Schultze, Maithilee Mitra, Jinhee Hur, Parul Christian, Alain B. Labrique, and Keith P. West Jr. 2019. "Dietary patterns of $>30,000$ adolescents $9-15$ years of age in rural Bangladesh." Annals of the New York Academy of Sciences 0 (0). doi: 10.1111/nyas.14207.

UIS, UNESCO. 2019. New Methodology Shows that 258 Million Children, Adolescents and Youth Are Out of School. Canada: UNESCO.

Vereecken, Carine, and Lea Maes. 2010. "Young children's dietary habits and associations with the mothers' nutritional knowledge and attitudes." Appetite 54 (1):44-51. doi: https://doi.org/10.1016/j.appet.2009.09.005.

Viner, Russell M., Dougal S. Hargreaves, Joseph Ward, Chris Bonell, Ali H. Mokdad, and George Patton. 2017. "The health benefits of secondary education in adolescents and young adults: An international analysis in 186 low-, middle- and high-income countries from 1990 to 2013." SSM - Population Health 3:162-171. doi: https://doi.org/10.1016/j.ssmph.2016.12.004.

WHO. 2007a. "Child growth standards: Length/height-for-age." World Health Organization, accessed 28/09/2019. https://www.who.int/childgrowth/standards/height for age/en/.

WHO. 2007b. "Growth reference 5-19 years: BMI-for-age (5-19 years)." World Health Organization, accessed 28/09/2019. https://www.who.int/growthref/who2007 bmi for age/en/.

WHO. 2020. "Section 4: Guide to Physical Measurements (Step 2) " In The WHO STEPS Surveillance Manual: WHO STEPwise Approach to Chronic Disease Risk-Factor Surveillance edited by WHO Geneva STEPS team. Geneva: WHO. 